\title{
Decision support for computed tomography in the emergency department: a multicenter cluster-randomized controlled trial
}

\author{
James E. Andruchow ${ }^{1,3}$ (1) - Daniel Grigat ${ }^{2}$. Andrew D. McRae ${ }^{1,3} \cdot$ Grant Innes $^{1,3} \cdot$ Shabnam Vatanpour ${ }^{1}$. \\ Dongmei Wang ${ }^{1} \cdot$ Monica Taljaard ${ }^{4,5} \cdot$ Eddy Lang $^{1,3}$
}

Received: 25 March 2021 / Accepted: 17 June 2021 / Published online: 5 August 2021

(C) The Author(s), under exclusive licence to Canadian Association of Emergency Physicians (CAEP)/ Association Canadienne de Médecine d'Urgence (ACMU) 2021

\begin{abstract}
Objectives Clinical decision support may facilitate evidence-based imaging, but most studies to date examining the impact of decision support have used non-randomized designs which limit the conclusions that can be drawn from them. This randomized trial examines if decision support can reduce computed tomography (CT) utilization for patients with mild traumatic brain injuries and suspected pulmonary embolism in the emergency department. This study was funded by a competitive public research grant and registered on ClinicalTrials.gov (NCT02410941).

Methods Emergency physicians at five urban sites were assigned to voluntary decision support for CT imaging of patients with either head injuries or suspected pulmonary embolism using a cluster-randomized design over a 1-year intervention period. The co-primary outcomes were CT head and CT pulmonary angiography utilization. CT pulmonary angiography diagnostic yield (proportion of studies diagnostic for acute pulmonary embolism) was a secondary outcome.

Results A total of 225 physicians were randomized and studied over a 2-year baseline and 1-year intervention period. Physicians interacted with the decision support in $38.0 \%$ and $45.0 \%$ of eligible head injury and suspected pulmonary embolism cases, respectively. A mixed effects logistic regression model demonstrated no significant impact of decision support on head CT utilization (OR 0.93, 95\% CI $0.79-1.10, p=0.31$ ), CT pulmonary angiography utilization (OR $0.98,95 \%$ CI $0.88-1.11, p=0.74$ ) or diagnostic yield (OR $1.23,95 \%$ CI $0.96-1.65, p=0.10$ ). However, overall CT pulmonary diagnostic yield (17.7\%) was almost three times higher than that reported by a recent large US study, suggesting that selective imaging was already being employed.

Conclusion Voluntary decision support addressing many commonly cited barriers to evidence-based imaging did not significantly reduce CT utilization or improve diagnostic yield but was limited by low rates of participation and high baseline rates of selective imaging. Demonstrating value to clinicians through interventions that improve workflow is likely necessary to meaningfully change imaging practices.
\end{abstract}

Keywords Computerized decision support · Computed tomography · Mild traumatic brain injury · Pulmonary embolism · Emergency medicine $\cdot$ Evidence-based medicine

James E. Andruchow

andruchow.james@gmail.com

1 Department of Emergency Medicine, University of Calgary

Cumming School of Medicine, Foothills Medical Centre

Room C-231, 1403-29st NW, Calgary, AB T2N 2T9, Canada

2 Alberta Health Services, Calgary, AB, Canada

3 Department of Community Health Sciences, University of Calgary, Calgary, AB, Canada

4 Ottawa Hospital Research Institute, Ottawa, ON, Canada

5 School of Epidemiology and Public Health, University of Ottawa, Ottawa, ON, Canada 


\section{Résumé}

Objectifs Le soutien à la décision clinique peut faciliter l'imagerie fondée sur des données probantes, mais la plupart des études à ce jour examinant l'impact du soutien à la décision ont utilisé des modèles non randomisés qui limitent les conclusions qui peuvent en être tirées. Cet essai randomisé examine si l'aide à la décision peut réduire l'utilisation de la tomodensitométrie chez les patients présentant des lésions cérébrales traumatiques légères et une embolie pulmonaire présumée au service des urgences. Cette étude a été financée par une subvention de recherche publique compétitive et enregistrée sur ClinicalTrials.gov (NCT02410941).

Méthodes Les médecins urgentistes de cinq sites urbains ont été assignés à une aide à la décision volontaire pour l'imagerie par tomodensitométrie des patients présentant soit un traumatisme crânien, soit une suspicion d'embolie pulmonaire, selon une conception randomisée en grappes sur une période d'intervention d'un an. Les résultats co-primaires étaient l'utilisation de la tomodensitométrie de la tête et de la tomodensitométrie par angiographie pulmonaire. Le rendement diagnostique de l'angiographie pulmonaire par TDM (proportion d'études diagnostiquant une embolie pulmonaire aiguë) était un résultat secondaire.

Résultats Au total, 225 médecins ont été randomisés et étudiés au cours d'une période de référence de deux ans et d'une période d'intervention d'un an. Les médecins ont interagi avec l'aide à la décision dans 38,0\% et 45,0\% des cas admissibles de blessure à la tête et d'embolie pulmonaire soupçonnée, respectivement. Un modèle de régression logistique à effets mixtes n'a démontré aucun impact significatif de l'aide à la décision sur l'utilisation de la tomodensitométrie de la tête (OR 0,93, IC $95 \%$ 0,79-1,10, p = 0,31), l'utilisation de l'angiographie pulmonaire par tomodensitométrie (OR 0,98, IC 95\% 0,88-1,11, p $=0,74)$ ou le rendement diagnostique (OR 1,23, IC $95 \% 0,96-1,65, \mathrm{p}=0,10)$. Toutefois, le rendement global du diagnostic pulmonaire par TDM $(17,7 \%)$ était près de trois fois supérieur à celui rapporté par une étude récente aux États-Unis, ce qui laisse supposer que l'imagerie sélective était déjà utilisée.

Conclusions L'aide à la décision volontaire visant à éliminer de nombreux obstacles fréquemment cités à l'imagerie fondée sur des données probantes n'a pas réduit de façon significative l'utilisation de la tomodensitométrie ni amélioré le rendement diagnostique, mais a été limitée par de faibles taux de participation et des taux de base élevés d'imagerie sélective. La démonstration de la valeur pour les cliniciens par des interventions qui améliorent le flux de travail est probablement nécessaire pour changer de manière significative les pratiques d'imagerie.

\section{Clinician's capsule}

\section{What is known about the topic?}

Clinical decision support has been proposed as an effective intervention to facilitate evidence-based diagnostic imaging.

\section{What did this study ask?}

Can electronic decision support improve CT utilization and yield for ED patients with head injuries and suspected pulmonary embolism?

\section{What did this study find?}

Decision support effectiveness was limited by low physician engagement and did not significantly impact CT utilization or diagnostic yield.

\section{Why does this study matter to clinicians?}

While decision support can address many barriers to evidence-based imaging, effecting meaningful practice change requires demonstrating value to clinicians.

\section{Introduction}

Computed tomography (CT) is an essential diagnostic tool; however, utilization has grown rapidly over the past two decades [1,2], leading to concerns about cost [3], radiation exposure and consequent cancer risk [4,5], overdiagnosis of clinically insignificant disease [6], incidental findings leading to unnecessary testing and treatment [7], and variation among physicians $[8,9]$, suggesting opportunities for practice improvement exist. Consequently, evidence-based clinical decision rules have been developed to avoid unnecessary imaging for low-risk patients.

Two clinical scenarios for which validated decision rules exist to guide CT imaging are mild traumatic brain injury [10-12] and suspected pulmonary embolism [13-16], and Canadian and American Choosing Wisely recommendations suggest avoiding CT imaging for patients identified as low risk by these rules $[17,18]$. However, despite robust evidence supporting their use, implementation efforts have met with limited success [19]. Commonly cited barriers include difficulty in remembering and applying decision rules, threats to physician autonomy, workflow concerns, uncertainty with regard to patient outcomes, patient/colleague expectations and potential medicolegal risks [20,21]. While electronic clinical decision support has the potential to address many of these concerns; prior implementations 
have demonstrated modest reductions in CT utilization at best [22-30]. Moreover, the bulk of these studies have used non-randomized designs which are prone to bias and influence of temporal trends, tempering the conclusions that can be drawn from them [31].

This study used a randomized design to determine if electronic decision support can reduce unnecessary $\mathrm{CT}$ imaging for low-risk emergency department (ED) patients with head injuries or suspected pulmonary embolism. Our primary outcome was CT utilization, as defined by the proportion of eligible patients with CT performed. We hypothesized that the intervention would result in clinically meaningful absolute decreases in CT utilization of at least 5\% (11\% relative decrease) among head injury patients and $1 \%(15 \%$ relative decrease) among patients with suspected pulmonary embolism.

\section{Methods}

\section{Study design, setting and time period}

This prospective multicenter cluster-randomized controlled trial was conducted at five urban acute care sites (one level one trauma center, three community EDs and one urgent care center) in Calgary, Alberta, Canada from August 1, 2014 to August 30, 2017. Combined patient visits exceeded 390,000 annually during the study period. This study was approved by the University of Calgary Conjoint Health Research Ethics Board (REB14-0650) with a waiver of consent for physician participation and collection of patient-level data, was registered on ClinicalTrials.gov (NCT02410941) and was funded by a competitive research grant from Alberta Innovates Health Solutions.

\section{Population}

All emergency staff physicians at the five study sites were eligible for inclusion in the study. Physicians were excluded if they were trainees or had less than 10 eligible patient encounters in either the baseline or intervention periods (to ensure adequate sample size for data analysis and opportunity for exposure to decision support). Patient encounters were eligible for inclusion in the study if they were 18 years or older and attended one of the five study sites with a Canadian Triage and Acuity Scale (CTAS) 2-5 [32]. CTAS 1 (highest acuity) encounters were excluded given the higher likelihood of requiring emergent $\mathrm{CT}$ imaging and to avoid any inadvertent delays in care for critically ill patients. Encounters with a Canadian Emergency Department Information Systems (CEDIS) [33] chief complaint of "head injury" were eligible for the head injury analysis and encounters with chief complaints of "shortness of breath" or "chest pain" were eligible for the suspected pulmonary embolism analysis. These complaints were chosen to avoid inappropriate decision support triggers for other clinical scenarios (e.g., CT head to rule out stroke, D-dimer to rule out isolated deep venous thrombosis).

\section{Intervention}

A balanced incomplete block cluster-randomized design with physicians as the unit of randomization was employed. All physicians at the five study sites were randomized in a $1: 1$ ratio to receive decision support for either CT imaging of patients with head injury or suspected pulmonary embolism. Decision support tools were developed with a multidisciplinary team in accord with best practices [34, 35 ] and refined based on end-user testing. Head injury decision support automatically opened in a pop-up window whenever a non-contrast CT head was ordered for an eligible patient, prompted the user to complete the Canadian CT Head Rule, then provided an imaging recommendation, quantitative risk estimate of 7-day neurosurgical intervention and patient handout. Decision support for suspected pulmonary embolism triggered whenever a D-dimer or CT pulmonary angiogram was ordered for an eligible patient. The tool confirmed the indication for the test and prompted the physician to complete the 2-level Wells Score, Pulmonary Embolism Rule-out Criteria (PERC) and/or age-adjusted $\mathrm{D}$-dimer as clinically indicated, then provided a quantitative estimate of 90-day venous thromboembolism risk, imaging recommendation and patient handout (Fig. 1). Performance reports quantifying individual physicians' CT utilization rates and decision support adherence compared against their anonymized peers were distributed quarterly.

\section{Outcome measures}

Eligible patient encounters and CT utilization were identified from administrative data for the 2 years prior to the intervention (to provide baseline data) and for the 1-year following implementation. Patient demographics including age, sex, CTAS score, mode of arrival, ED length of stay, disposition, CT imaging, return ED visits and admissions were also retrieved from administrative data. An index visit was defined as the first visit for an eligible patient during the intervention period. Return visits were defined as a repeat ED visit for any reason during the follow-up period (30 days for head injury and 90 days for suspected pulmonary embolism patients), in accord with prior literature.

The primary outcome of CT utilization by physicians, defined as the proportion of eligible encounters with either non-contrast head CT (head injury arm) or CT pulmonary angiography (suspected pulmonary embolism arm) performed on the index visit, was calculated from administrative 
Decision Support Algorithm for Patients with Suspected PE

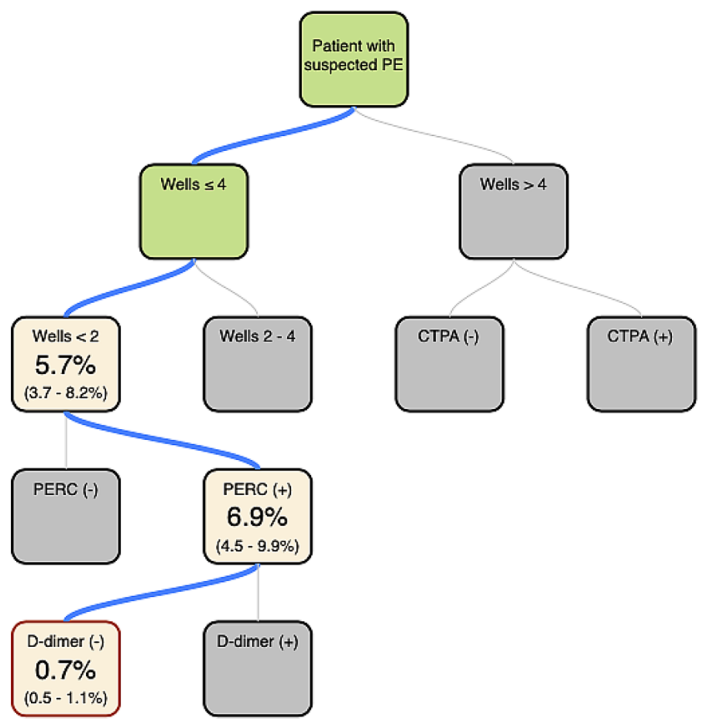

Fig. 1 Screenshot of decision support for suspected pulmonary embolism

data. For the suspected pulmonary embolism analysis, the secondary outcome of diagnostic yield (proportion of studies diagnostic for acute pulmonary embolism) was calculated based on manual review of diagnostic imaging reports by a trained research assistant blinded to the randomization status of the ordering clinician, with physician adjudication of indeterminate cases.

\section{Data analysis}

A generalized linear mixed effects model (binary distribution, logit link function) was used to assess whether CT utilization or diagnostic yield differed between intervention and control groups. The unit of analysis was the individual patient. We used the constrained baseline approach of Hooper et al. [36] to test the between-arm difference at post-intervention, controlling for baseline by including fixed effects for time (pre- and post-intervention), and group by time interaction, and adjusting for pre-specified patient covariates: age and sex. As the trial included all available physicians, we determined the detectable difference for each of the two primary trial outcomes, using the method of Teerenstra [37]. Because the Canadian CT head rule considers all head injury patients aged 65 years and older high risk, a pre-specified subgroup analysis was performed for patients aged 18-64 years and $\geq 65$ years. Coefficients of variation and intracluster correlation coefficients were calculated to assess if there was any impact on inter-physician variability for CT utilization. Secondary outcomes were tabulated descriptively for the intervention period.

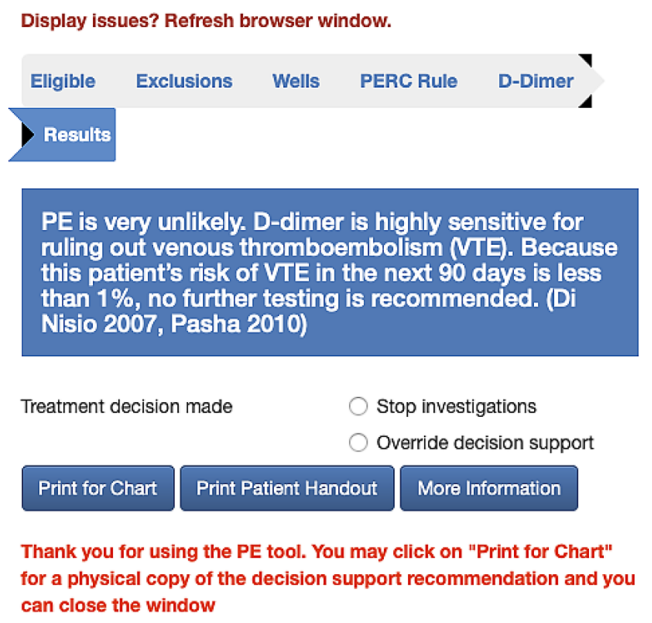

\section{Sample size}

For the head injury analysis, we determined that 100 physicians in each arm with an average of 25 patients per physician would achieve $80 \%$ power to detect a clinically meaningful $5 \%$ absolute (11\% relative) CT utilization reduction from the baseline rate of $\sim 42 \%$, assuming an intracluster correlation coefficient of 0.1 , a correlation with baseline of 0.8 , and using a two-sided significance level of $5 \%$. We applied a cluster size coefficient of variation of $50 \%$ to account for variability in cluster sizes across physicians. For suspected pulmonary embolism, 100 physicians in each arm with an average of 150 patients per physician would achieve $80 \%$ power to detect a clinically meaningful $1 \%$ absolute (15\% relative) CT utilization reduction from the baseline rate of $\sim 6.5 \%$, assuming an intracluster correlation coefficient of 0.02 , a correlation with baseline of 0.8 , a coefficient of cluster size variation of $50 \%$, and using a two-sided significance level of 5\%. All statistical analyses were conducted using SAS v9.4 (SAS Institute Inc., Cary, NC, USA).

\section{Results}

A total of 225 physicians were randomized (109 to head injury and 116 to suspected pulmonary embolism interventions) during the study period. Data were collected for a 2-year baseline period prior to the study (August 1, 2014-August 1, 2016) and for 1-year following implementation (August 2, 2016-August 30, 2017). A total of 20 
physicians were excluded because they had less than 10 eligible patient encounters, leaving 104 physicians randomized to head injury and 101 randomized to the suspected pulmonary embolism interventions available for the analysis. Patient demographics in the post-intervention period were similar between intervention and control groups (Table 1).

\section{Head injury}

Intervention physicians triggered decision support 1071 times, and voluntarily interacted with it 407 times (38.0\%). CT head utilization was similar for both intervention and control physicians in the baseline $(41.5 \%$ vs $42.9 \%)$ and post-intervention periods ( $39.8 \%$ vs $42.7 \%$ ), respectively, (Table 2; Fig. 2) and the between-arm difference in the intervention period was not statistically significant in the adjusted mixed effects model (OR 0.91, 95\% CI 0.74-1.08, $p=0.31)$.

The stratified subgroup analysis showed that for patients aged 18-64 years, CT head utilization was similar for both intervention and control physicians in the baseline $(31.8 \%$ vs $32.4 \%$ ) and post-intervention periods ( $28.3 \%$ vs $30.7 \%$ ), respectively, (Table 2), and the between-arm difference in the intervention period was not statistically significant (adjusted OR 0.91, 95\% CI 0.76-1.11). For patients aged 65-years and older, results were similar for intervention and control physicians in the baseline $(73.4 \%$ vs $76.2 \%)$ and post-intervention periods ( $71.7 \%$ vs $73.7 \%$ ), respectively, and the between-arm difference in the intervention period was not statistically significant (adjusted OR $0.94,95 \%$ CI $0.69-1.27, p=0.74)$.

\section{Suspected pulmonary embolism}

Intervention physicians triggered decision support 1829 times, and voluntarily interacted with it 823 times (45.0\%). Of 32,144 eligible patient encounters during the intervention period, CT pulmonary angiography was performed in 1995 (6.2\%) of cases. Utilization for eligible patients was similar between intervention and control physicians in the baseline period $(6.3 \%$ vs $6.5 \%)$ and in the post-intervention period (6.2\% vs $6.2 \%$ ) respectively (Table 2 ; Fig. 2). No statistically significant difference in utilization between groups in the intervention period was noted in the mixed effects model (OR 0.98, 95\% CI 0.87-1.11, $p=0.74$ ). Of 1995 CT pulmonary angiography studies performed during the intervention period, $354(17.7 \%)$ were diagnostic for acute pulmonary embolism. Diagnostic yield was similar between intervention and control physicians in both the baseline (from 18.5\% vs $17.1 \%$ ) and post-intervention periods ( $19.5 \%$ vs $16.1 \%)$, respectively, and the between-arm difference in the intervention period was not statistically significant (OR 1.23, 95\% CI $0.96-1.65, p=0.10$ ).

\section{Secondary outcomes}

Patient outcomes are presented descriptively (Table 3 ). There were no clinically meaningful differences noted between intervention and control groups for any of the variables measured. Between-physician measures of variability were similar in both the baseline and post-intervention periods (head CT utilization: coefficient of variation 0.426 vs 0.455 ; intracluster correlation coefficient 0.094 vs 0.097 ; CT pulmonary angiography utilization: coefficient of variation
Table 1 Patient characteristics-Postintervention period only

\begin{tabular}{|c|c|c|c|c|}
\hline \multirow[t]{2}{*}{ Characteristic } & \multicolumn{2}{|c|}{ Head injury cohort } & \multicolumn{2}{|c|}{$\begin{array}{l}\text { Suspected pulmonary embolism } \\
\text { cohort }\end{array}$} \\
\hline & Intervention & Control & Intervention & Control \\
\hline Sample size $(n)$ & 3085 & 2602 & 15,330 & 16,814 \\
\hline Age (median, IQR) & $44(28,66)$ & $45(28,68)$ & $56(39,70)$ & $54(38,69)$ \\
\hline Male sex $(\%)$ & $1587(51.4)$ & $1387(53.3)$ & $7566(49.4)$ & $8293(49.3)$ \\
\hline \multicolumn{5}{|l|}{ Triage acuity scale } \\
\hline CTAS 1 & - & - & - & - \\
\hline CTAS 2 & $679(22.0)$ & $589(22.6)$ & $10,777(70.3)$ & $11,434(68.0)$ \\
\hline CTAS 3 & $1621(52.5)$ & $1412(54.3)$ & 3471 (22.6) & $4008(23.8)$ \\
\hline CTAS 4 & $785(25.4)$ & $601(23.1)$ & $1022(6.7)$ & $1312(7.8)$ \\
\hline CTAS 5 & $0(0)$ & $0(0)$ & $60(0.4)$ & $60(0.4)$ \\
\hline \multicolumn{5}{|l|}{ Arrival mode (\%) } \\
\hline Private vehicle & $2073(67.2)$ & $1671(64.2)$ & $10,808(70.5)$ & $12,253(72.9)$ \\
\hline Ground ambulance & $1004(32.5)$ & $925(35.5)$ & $4482(29.2)$ & $4514(26.8)$ \\
\hline Air ambulance & $2(0.1)$ & $2(0.1)$ & $8(0.1)$ & $6(0.0)$ \\
\hline Other/unspecified & $6(0.2)$ & $4(0.2)$ & $32(0.2)$ & $41(0.2)$ \\
\hline
\end{tabular}


Table 2 CT utilization and diagnostic yield by clinical scenario

\begin{tabular}{|c|c|c|c|c|c|c|c|}
\hline \multirow{2}{*}{\multicolumn{2}{|c|}{ Head injury cohort }} & \multicolumn{2}{|c|}{$\begin{array}{l}\text { Baseline period } \\
\text { (Aug 1, 2014-Aug 1, 2016) }\end{array}$} & \multicolumn{2}{|c|}{$\begin{array}{l}\text { Post-intervention period } \\
\text { (Aug 2, 2016-Aug 30, 2017) }\end{array}$} & \multirow[b]{3}{*}{$\begin{array}{l}\text { Adjusted Odds } \\
\text { Ratio (95\% CI) }\end{array}$} & \multirow[b]{3}{*}{$p$ value } \\
\hline & & & & & & & \\
\hline Randomization & $\begin{array}{l}\text { Physicians } \\
N\end{array}$ & $\begin{array}{l}\text { Patient } \\
\text { encounters } N\end{array}$ & $\begin{array}{l}\text { Head CT } \\
\text { Performed } N(\%)\end{array}$ & $\begin{array}{l}\text { Patient } \\
\text { encounters } N\end{array}$ & $\begin{array}{l}\text { Head CT } \\
\text { Performed } N(\%)\end{array}$ & & \\
\hline \multicolumn{8}{|c|}{ CT head utilization, all ages } \\
\hline Intervention & 101 & 5136 & $2133(41.5)$ & 3085 & $1227(39.8)$ & $0.91(0.74-1.08)$ & 0.31 \\
\hline Control & 103 & 4614 & $1979(42.9)$ & 2602 & $1112(42.7)$ & & \\
\hline Total & 204 & 9750 & $4112(42.2)$ & 5687 & $2339(41.1)$ & & \\
\hline \multicolumn{8}{|c|}{ CT head utilization, ages $18-64$} \\
\hline Intervention & 101 & 3933 & $1250(31.8)$ & 2272 & $644(28.3)$ & $0.91(0.76,1.11)$ & 0.36 \\
\hline Control & 103 & 3505 & $1134(32.4)$ & 1872 & $574(30.7)$ & & \\
\hline Total & 204 & 7438 & $2384(32.1)$ & 4144 & $1218(29.4)$ & & \\
\hline \multicolumn{8}{|c|}{ CT head utilization, ages $65+$} \\
\hline Intervention & 100 & 1203 & $883(73.4)$ & 813 & $583(71.7)$ & $0.94(0.69,1.27)$ & 0.68 \\
\hline Control & 99 & 1109 & $845(76.2)$ & 730 & $538(73.7)$ & & \\
\hline Total & 199 & 2312 & $1728(74.7)$ & 1543 & $1121(72.7)$ & & \\
\hline \multicolumn{8}{|c|}{ Suspected pulmonary embolism cohort } \\
\hline Randomization & $\begin{array}{l}\text { Physicians } \\
N\end{array}$ & $\begin{array}{l}\text { Patient encounters } \\
N\end{array}$ & $\begin{array}{l}\text { CT Performed } \\
N(\%)\end{array}$ & $\begin{array}{l}\text { Patient encounters } \\
N\end{array}$ & $\begin{array}{l}\text { CT Performed } \\
N(\%)\end{array}$ & $\begin{array}{l}\text { Adjusted Odds } \\
\text { Ratio (95\% CI) }\end{array}$ & $p$ value \\
\hline \multicolumn{8}{|l|}{ CT utilization } \\
\hline Intervention & 104 & 28,328 & $1790(6.3)$ & 15,330 & $947(6.2)$ & $0.98(0.87,1.11)$ & 0.74 \\
\hline Control & 101 & 29,891 & $1947(6.5)$ & 16,814 & $1048(6.2)$ & & \\
\hline Total & 205 & 58,219 & $3737(6.4)$ & 32,144 & $1995(6.2)$ & & \\
\hline Randomization & $\begin{array}{l}\text { Physicians } \\
N\end{array}$ & $\begin{array}{l}\text { CT Performed } \\
N\end{array}$ & $\begin{array}{l}\text { PE Diagnosed } \\
N(\%)\end{array}$ & $\begin{array}{l}\text { CT Performed } \\
N\end{array}$ & $\begin{array}{l}\text { PE Diagnosed } \\
N(\%)\end{array}$ & $\begin{array}{l}\text { Adjusted Odds } \\
\text { Ratio (95\% CI) }\end{array}$ & $p$ value \\
\hline \multicolumn{8}{|c|}{ CT diagnostic yield } \\
\hline Intervention & 91 & 1790 & $332(18.5)$ & 947 & $185(19.5)$ & $1.23(0.96,1.65)$ & 0.10 \\
\hline Control & 83 & 1947 & $333(17.1)$ & 1048 & $169(16.1)$ & & \\
\hline Total & 174 & 3737 & $665(17.8)$ & 1995 & 354 (17.7) & & \\
\hline
\end{tabular}

0.692 vs 0.706 , intracluster correlation coefficient 0.02 in both periods).

\section{Discussion}

\section{Interpretation of findings}

To our knowledge, this is the first randomized multicenter trial examining the impact of electronic decision support on CT utilization in the ED, and is important because the bulk of prior studies have used non-randomized designs prone to bias and confounding. Moreover, the comprehensive intervention addressed most of the commonly cited barriers to evidence-based imaging. Unfortunately, we were unable to demonstrate a statistically significant impact of decision support on CT utilization and diagnostic yield, although point estimates suggested a weak signal of effect. While we considered the possibility that increased utilization among low-users could have offset reduced utilization among highusers and concealed a benefit signal, we did not detect any reduction in inter-physician variability in our analysis. The limited effectiveness of the intervention is likely owing to low rates of voluntary physician interaction which appeared to attenuate further over time. These findings imply that simple provision of decision support is insufficient to meaningfully change imaging practices, and that future interventions must be perceived by clinicians as adding value to their practice to be successful.

\section{Comparison to previous studies}

While it is difficult to directly compare our CT pulmonary angiography utilization data with prior literature because of differing denominators used, the $17.7 \%$ overall diagnostic yield observed here is almost triple the $6.3 \%$ 
Fig. 2 CT utilization and CT pulmonary angiography diagnostic yield by month, pre- and post-decision support implementation
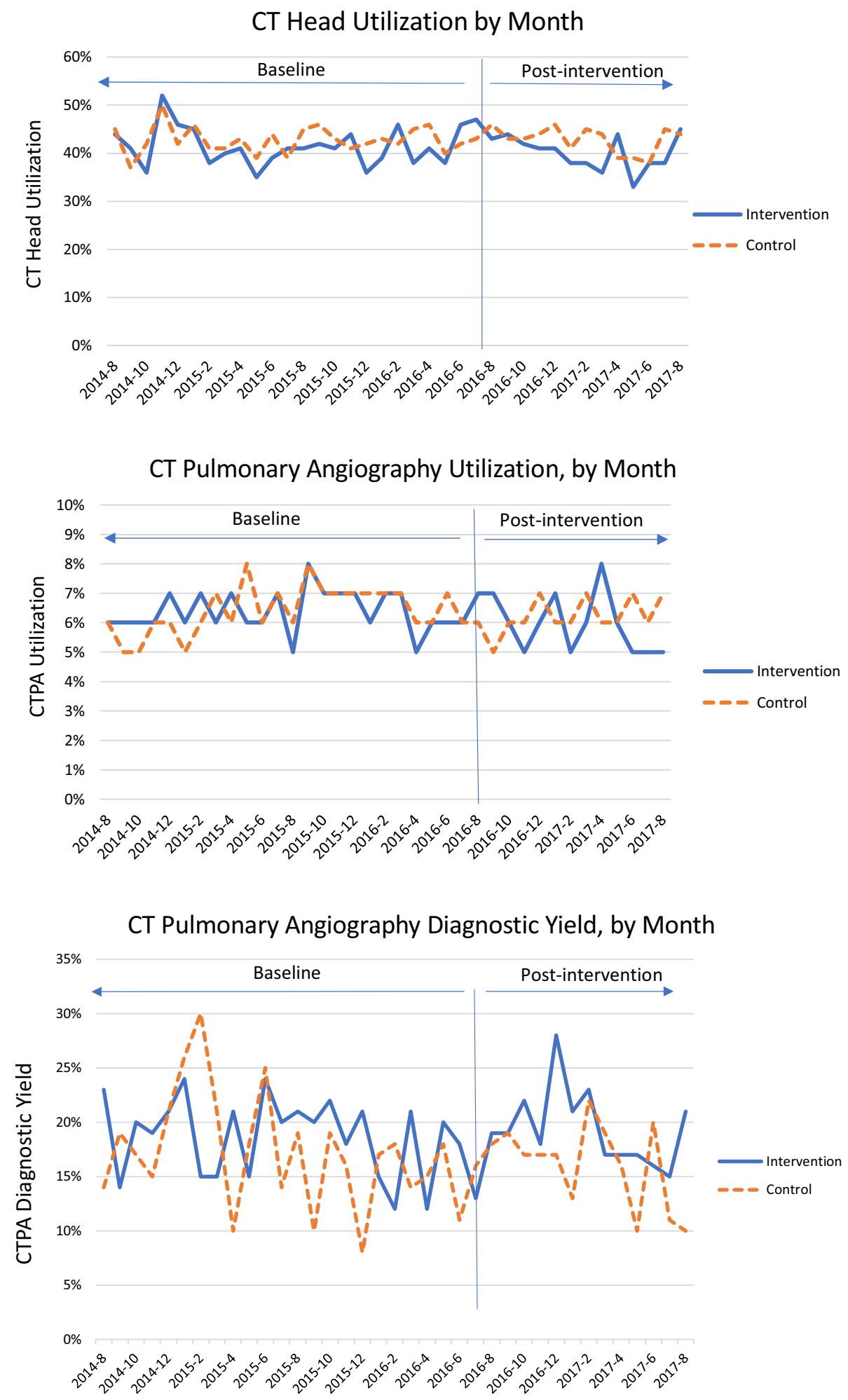

yield reported in a recent United States sample of over 300 hospital regions [38]. Similarly, head CT utilization appeared to be lower in this cohort, where only $43 \%$ of head injury patients underwent CT compared to $63-76 \%$ in prior studies [19]. These findings suggest that selective CT imaging was already being used prior to the intervention, and may have limited the potential for further improvements. 
Table 3 Patient outcomes (intervention period only)

\begin{tabular}{|c|c|c|}
\hline \multicolumn{3}{|l|}{ Head injury cohort } \\
\hline Index visit outcomes & Intervention & Control \\
\hline Encounters & 3085 & 2602 \\
\hline Head CT performed & $1227(39.8)$ & $1112(42.7)$ \\
\hline \multicolumn{3}{|l|}{ Disposition } \\
\hline Discharged $N(\%)$ & $2872(93.1)$ & $2395(92.0)$ \\
\hline Admitted $N(\%)$ & $163(5.3)$ & $152(5.8)$ \\
\hline Transferred $N(\%)$ & $49(1.6)$ & $55(2.1)$ \\
\hline Deceased $N(\%)$ & $1(0.0)$ & $0(0.0)$ \\
\hline ED length of stay-discharged patients-min (IQR) & $196(130,288)$ & $200(134,294)$ \\
\hline \multicolumn{3}{|l|}{ Index traumatic head injury diagnoses } \\
\hline Epidural Hematoma (S06.4) N (\%) & $2(0.1)$ & $2(0.1)$ \\
\hline Subdural Hemorrhage (S06.5) $N(\%)$ & $30(1.0)$ & $41(1.6)$ \\
\hline Subarachnoid Hemorrhage (S06.6) $N(\%)$ & $23(0.7)$ & $30(1.2)$ \\
\hline Intracranial injury unspecified (S06.9) $N(\%)$ & $82(2.7)$ & $32(1.2)$ \\
\hline Unspecified injury of head (S09.9) $N(\%)$ & $647(21.0)$ & $601(23.1)$ \\
\hline \multicolumn{3}{|l|}{ 30-day outcomes } \\
\hline 30-day Head CT (includes index visit) $N(\%)$ & $119(3.9)$ & $121(4.7)$ \\
\hline 30-day ED revisit $N(\%)$ & $525(17.0)$ & $458(17.6)$ \\
\hline 30-day hospitalization $N(\%)$ & $147(4.8)$ & $131(5.0)$ \\
\hline \multicolumn{3}{|l|}{ 30-day traumatic head injury ICD-10 diagnoses (includes index visit) } \\
\hline Epidural Hematoma (S06.4) $N(\%)$ & $3(0.1)$ & $4(0.2)$ \\
\hline Subdural Hemorrhage (S06.5) $N(\%)$ & $48(1.6)$ & $65(2.5)$ \\
\hline Subarachnoid Hemorrhage (S06.6) $N(\%)$ & $32(1.0)$ & $41(1.6)$ \\
\hline Intracranial injury unspecified (S06.9) $N(\%)$ & $83(2.7)$ & $32(1.2)$ \\
\hline Unspecified injury of head (S09.9) $N(\%)$ & $682(22.1)$ & $623(23.9)$ \\
\hline 30-day death (includes index visit) $N(\%)$ & $24(0.8)$ & $20(0.8)$ \\
\hline \multicolumn{3}{|l|}{ Suspected pulmonary embolism cohort } \\
\hline Index visit outcomes & Intervention & Control \\
\hline Encounters & 15,330 & 16,814 \\
\hline CT Performed $N(\%)$ & $947(6.2)$ & $1048(6.2)$ \\
\hline Index visit PE diagnosis $N(\%)$ & $185(1.2)$ & $169(1.0)$ \\
\hline \multicolumn{3}{|l|}{ Disposition } \\
\hline Discharged $N(\%)$ & $11,624(75.8)$ & $13,061(77.7)$ \\
\hline Admitted $N(\%)$ & $3356(21.9)$ & $3324(19.8)$ \\
\hline Transferred $N(\%)$ & $195(1.3)$ & $247(1.5)$ \\
\hline Deceased $N(\%)$ & $15(0.1)$ & $20(0.1)$ \\
\hline ED length of stay (discharged patients only) minutes (IQR) & $245(173,331)$ & $234(167,316)$ \\
\hline \multicolumn{3}{|l|}{ 90-day outcomes } \\
\hline 90-day CT (includes index visit) $N(\%)$ & $1098(7.2)$ & $1208(7.2)$ \\
\hline 90-day ED revisit $N(\%)$ & $4185(27.3)$ & $4516(26.9)$ \\
\hline 90 -day hospitalization $N(\%)$ & $1532(10.0)$ & $1598(9.5)$ \\
\hline 90-day PE ICD-10 diagnosis (I26) (includes index visit) $N(\%)$ & $238(1.6)$ & $234(1.4)$ \\
\hline 90-day death (includes index visit) $N(\%)$ & $22(0.1)$ & $28(0.2)$ \\
\hline
\end{tabular}

\section{Strengths and limitations}

The randomized multicentre design and comprehensive intervention are major strengths of this study. The primary limitation is the voluntary nature of the intervention, permitting physicians to neither interact with the decision support, nor follow its recommendation. Owing to technical limitations, decision support could not be integrated directly into the order entry software and opened in an external window which could be ignored by the physician. However, 
mandatory interaction has limitations. In fact, a prior study of decision support in the ED demonstrated that almost $10 \%$ of data entered by clinicians was erroneous, raising the possibility that clinicians were "gaming" mandatory data entry to avoid intrusive alerts or avoid appearing non-compliant with institutional guidelines [39]. In addition, the implementation of decision support at the time of CT ordering (when an imaging decision has already been made), likely further limited its impact. Finally, it is possible that because the decision rules used in the study have demonstrated limited impact in prior real-world implementations [19, 26], newer simplified tools such as the YEARS criteria [40] may be more easily incorporated into practice.

\section{Clinical implications}

These findings suggest that while decision support may have a role in facilitating evidence-based imaging, future interventions must demonstrate value for physicians to be widely adopted. Examples may include simplified tools integrated into charting to decrease cognitive load and improve documentation efficiency during patient assessment and/or incentives for adherence to evidence-based guidelines. Direct consultation with clinicians is recommended to design interventions that would be perceived as helpful, and determine how best to implement them in the local practice setting.

\section{Research implications}

Future efforts to facilitate evidence-based imaging might begin with end-user consultations and focus on upstream interventions that improve physician workflow, implementation in settings where opportunity for improvement is greatest and possibly incentives for evidence-based practice.

\section{Conclusion}

This randomized study used a comprehensive decision support intervention to address many of the previously cited barriers to evidence-based CT imaging, but was limited by low levels of participation and was unable to significantly impact CT utilization or diagnostic yield. Understanding local needs through direct consultation and demonstrating value to clinicians through interventions that improve workflow are likely necessary to effect meaningful practice change.

Acknowledgements We would like to acknowledge the significant contributions of Katrina Koger in assisting with data collection and review to make this study possible.

Author contributions All authors participated in research design, execution, analysis and manuscript preparation. Study concept and
design-JA, DG, AM, GI, SV, DW, MT, EL. Acquisition of the dataJA, DG, SV, DW. Analysis and interpretation of the data-JA, DG, AM, GI, SV, DW, MT, EL. Drafting of the manuscript-JA, DG, AM, GI, MT, EL. Critical revision of the manuscript-JA, DG, AM, GI, SV, DW, MT, EL. Statistical expertise-JA, SV, DW, MT. Acquisition of funding-JA, DG, AM, GI, DW, EL.

Funding This study was funded by a competitive unrestricted research Grant (201300468) from Alberta Innovates Health Solutions (AIHS): Partnership for Research and Innovation in the Health System (PRIHS).

Availability of data and materials The data underlying this article cannot be shared publicly to protect the privacy of individuals that participated in the study. The data will be shared on reasonable request to the corresponding author with permission of Alberta Health Services and the University of Calgary Conjoint Health Research Ethics Board.

\section{Declarations}

Conflict of interest We have no competing interests to disclose.

\section{References}

1. Berdahl CT, Vermeulen MJ, Larson DB, Schull MJ. Emergency department computed tomography utilization in the United States and Canada. Ann Emerg Med. 2013;62(5):486-94.e3.

2. Mettler FA. Medical radiation exposure in the United States: 2006-2016 trends. Health Phys. 2019;116(2):126-8.

3. Smith-Bindman R, Miglioretti DL, Larson EB. Rising use of diagnostic medical imaging in a large integrated health system. Health Aff. 2008;27(6):1491-502.

4. Brenner DJ, Hall EJ. Computed tomography — an increasing source of radiation exposure. N Engl J Med. 2007;357(22):2277-84.

5. de González AB, Mahesh M, Kim K-P, Bhargavan M, Lewis $\mathrm{R}$, Mettler F, et al. Projected cancer risks from computed tomographic scans performed in the United States in 2007. Arch Intern Med. 2009;169(22):2071-7.

6. Wiener RS, Schwartz LM, Woloshin S. When a test is too good: how CT pulmonary angiograms find pulmonary emboli that do not need to be found. BMJ. 2013;347: f3368.

7. Anjum O, Bleeker H, Ohle R. Computed tomography for suspected pulmonary embolism results in a large number of nonsignificant incidental findings and follow-up investigations. Emerg Radiol. 2019;26(1):29-35.

8. Stiell IG, Wells GA, Vandemheen K, Laupacis A, Brison R, Eisenhauer MA, et al. Variation in ED use of computed tomography for patients with minor head injury. Ann Emerg Med. 1997;30(1):14-22.

9. Andruchow JE, Raja AS, Prevedello LM, Zane RD, Khorasani R. Variation in head computed tomography use for emergency department trauma patients and physician risk tolerance. Arch Intern Med. 2012;172(8):660-1.

10. Stiell IG, Wells GA, Vandemheen K, Clement C, Lesiuk H, Laupacis A, et al. The Canadian CT head rule for patients with minor head injury. Lancet. 2001;357(9266):1391-6.

11. Stiell IG, Clement CM, Rowe BH, Schull MJ, Brison R, Cass $\mathrm{D}$, et al. Comparison of the Canadian CT head rule and the New Orleans criteria in patients with minor head injury. JAMA. 2005;294(12):1511-8.

12. Harnan SE, Pickering A, Pandor A, Goodacre SW. Clinical decision rules for adults with minor head injury: a systematic review. J Trauma. 2011;71(1):245-51. 
13. Ceriani E, Combescure C, Le Gal G, Nendaz M, Perneger T, Bounameaux $\mathrm{H}$, et al. Clinical prediction rules for pulmonary embolism: a systematic review and meta-analysis. J Thromb Haemost. 2010;8(5):957-70.

14. Singh B, Mommer SK, Erwin PJ, Mascarenhas SS, Parsaik AK. Pulmonary embolism rule-out criteria (PERC) in pulmonary embolism-revisited: a systematic review and meta-analysis. Emerg Med J. 2013;30(9):701-6.

15. Nybo M, Hvas A-M. Age-adjusted D-dimer cut-off in the diagnostic strategy for deep vein thrombosis: a systematic review. Scand J Clin Lab Invest. 2017;77(8):568-73.

16. Konstantinides SV, Meyer G. The 2019 ESC guidelines on the diagnosis and management of acute pulmonary embolism. Eur Heart J. 2019;40(42):3453-5

17. American College of Emergency Physicians. An initiative of the ABIM foundation. Choosing wisely. http://www.choosingwisely. org/clinician-lists/. Accessed 26 Sep 2016

18. Cheng AHY, Campbell S, Chartier LB, Goddard T, Magee K, McEwen J, et al. Choosing Wisely Canada ${ }^{\circledR}$ : five tests, procedures and treatments to question in emergency medicine. CJEM. 2017;19(S2):S9-17.

19. Stiell IG, Clement CM, Grimshaw JM, Brison RJ, Rowe BH, Lee JS, et al. A prospective cluster-randomized trial to implement the Canadian CT head rule in emergency departments. CMAJ. 2010;182(14):1527-32.

20. Stiell IG, Bennett C. Implementation of clinical decision rules in the emergency department. Acad Emerg Med. 2007;14(11):955-9.

21. Curran JA, Brehaut J, Patey AM, Osmond M, Stiell I, Grimshaw JM. Understanding the Canadian adult CT head rule trial: use of the theoretical domains framework for process evaluation. Implement Sci. 2013;21(8):25.

22. Raja AS, Ip IK, Prevedello LM, Sodickson AD, Farkas C, Zane $\mathrm{RD}$, et al. Effect of computerized clinical decision support on the use and yield of CT pulmonary angiography in the emergency department. Radiology. 2012;262(2):468-74.

23. Dunne RM, Ip IK, Abbett S, Gershanik EF, Raja AS, Hunsaker A, et al. Effect of evidence-based clinical decision support on the use and yield of CT pulmonary angiographic imaging in hospitalized patients. Radiology. 2015;276(1):167-74.

24. Ip IK, Raja AS, Gupta A, Andruchow J, Sodickson A, Khorasani R. Impact of clinical decision support on head computed tomography use in patients with mild traumatic brain injury in the ED. Am J Emerg Med. 2015;33(3):320-5.

25. Jiménez D, Resano S, Otero R, Jurkojc C, Portillo AK, Ruiz-Artacho $\mathrm{P}$, et al. Computerised clinical decision support for suspected PE. Thorax. 2015;70(9):909-11.

26. Bookman K, West D, Ginde A, Wiler J, McIntyre R, Hammes A, et al. Embedded clinical decision support in electronic health record decreases use of high-cost imaging in the emergency department: EmbED study. Acad Emerg Med. 2017;24(7):839-45.

27. Mills AM, Ip IK, Langlotz CP, Raja AS, Zafar HM, Khorasani R. Clinical decision support increases diagnostic yield of computed tomography for suspected pulmonary embolism. Am J Emerg Med. 2018;36(4):540-4.
28. Sharp AL, Huang BZ, Tang T, Shen E, Melnick ER, Venkatesh AK, et al. Implementation of the Canadian CT head rule and its association with use of computed tomography among patients with head injury. Ann Emerg Med. 2018;71(1):54-63.e2.

29. Ballard DW, Kuppermann N, Vinson DR, Tham E, Hoffman JM, Swietlik M, et al. Implementation of a clinical decision support system for children with minor blunt head trauma who are at nonnegligible risk for traumatic brain injuries. Ann Emerg Med. 2019;73(5):440-51.

30. Goehler A, Moore C, Manne-Goehler JM, Arango J, D'Amato L, Forman HP, et al. Clinical decision support for ordering CTAPE studies in the emergency department-a pilot on feasibility and clinical impact in a tertiary medical center. Acad Radiol. 2019;26(8):1077-83.

31. Patterson BW, Pulia MS, Ravi S, Hoonakker PLT, SchoofsHundt A, Wiegmann D, et al. Scope and influence of electronic health record-integrated clinical decision support in the emergency department: a systematic review. Ann Emerg Med. 2019;74(2):285-96.

32. Bullard MJ, Musgrave E, Warren D, Unger B, Skeldon T, Grierson $\mathrm{R}$, et al. Revisions to the Canadian emergency department triage and acuity scale (CTAS) guidelines 2016. CJEM. 2017;19(S2):S18-27.

33. CTAS National Working Group, Grafstein E, Bullard MJ, Warren D, Unger B. Revision of the Canadian emergency department information system (CEDIS) presenting complaint list version 1.1. CJEM. 2008;10(2):151-73.

34. Bates DW, Kuperman GJ, Wang S, Gandhi T, Kittler A, Volk L, et al. Ten commandments for effective clinical decision support: making the practice of evidence-based medicine a reality. J Am Med Inform Assoc. 2003;10(6):523-30.

35. Khorasani R, Hentel K, Darer J, Langlotz C, Ip IK, Manaker S, et al. Ten commandments for effective clinical decision support for imaging: enabling evidence-based practice to improve quality and reduce waste. Am J Roentgenol. 2014;203(5):945-51.

36. Hooper R, Forbes A, Hemming K, Takeda A, Beresford L. Analysis of cluster randomised trials with an assessment of outcome at baseline. BMJ. 2018;20(360): k1121.

37. Teerenstra S, Eldridge S, Graff M, de Hoop E, Borm GF. A simple sample size formula for analysis of covariance in cluster randomized trials. Stat Med. 2012;31(20):2169-78.

38. Venkatesh AK, Agha L, Abaluck J, Rothenberg C, Kabrhel C, Raja AS. Trends and variation in the utilization and diagnostic yield of chest imaging for medicare patients with suspected pulmonary embolism in the emergency department. AJR Am J Roentgenol. 2018;210(3):572-7.

39. Gupta A, Raja AS, Khorasani R. Examining clinical decision support integrity: is clinician self-reported data entry accurate? J Am Med Inform Assoc. 2014;21(1):23-6.

40. van der Hulle T, Cheung WY, Kooij S, Beenen LFM, van Bemmel T, van Es J, et al. Simplified diagnostic management of suspected pulmonary embolism (the YEARS study): a prospective, multicentre, cohort study. Lancet. 2017;390(10091):289-97. 